Controversies

in

\section{Therapeutics}

\title{
Risks of dependence on benzodiazepine drugs: the importance of patient selection
}

\author{
Peter Tyrer
}

There is considerable concern, sometimes amounting to alarm, in many parts of the world about the risks of dependence on benzodiazepine drugs. Although in some ways this is understandable as benzodiazepines were for many years the most commonly prescribed group of drugs, the arguments about their continued use have often been oversimplified. A dangerous myth is developing that all people prescribed benzodiazepines will become chemically dependent on them and that it is only through a combination of unscrupulous drug advertising and irresponsible prescribing that these drugs continue to be given. The search is on for a scapegoat. "Somebody 'as to be summonsed," in the words of one of Stanley Holloway's Lancashire ditties, and the drug companies and doctors are the prime suspects.

Here I argue quite a different premise: it is patients who are primarily responsible for dependence on benzodiazepines, not through wilful abuse but because of the structure of their personality.

\section{Factors predisposing to dependence on benzodiazepines}

Not all patients prescribed benzodiazepines develop dependence even when they are prescribed them for a long time. This elementary fact is often ignored by those who calculate numbers of dependent patients from data on total prescribing. Unfortunately, there is no means of knowing whether a patient is dependent unless he or she has the symptoms of a withdrawal syndrome after stopping taking the drug or reducing the dose ${ }^{\prime}$ and therefore accurate figures of the incidence of dependence in those prescribed benzodiazepines are difficult to calculate. Another problem is that those referred to specialist clinics for help in withdrawing from the drugs are a highly selected sample, although reports from such clinics that most if not all their patients suffer an abstinence syndrome on withdrawal is not surprising. ${ }^{24}$ In our studies, however, in which patients were seen in general practice psychiatric clinics and were not specially referred for problems with dependence, the incidence of withdrawal symptoms was about a third. ${ }^{56}$ Even this may be an overestimate of the true incidence of dependence as patients referred to psychiatrists for any reason from primary care represent only a small proportion of those taking benzodiazepines regularly.

\section{Importance of personality state as a risk factor}

If two thirds of the population are not at serious risk of dependence on benzodiazepines it is particularly important to identify the minority that is at high risk

\section{EDITORIAL COMMENT}

Although differing in their views about the frequency of withdrawal symptoms from benzodiazepines, Drs Ashton and Tyrer broadly agree on important clinical matters. Firstly, a particular type of patient is much more likely to become dependent (and possibly quickly dependent) on benzodiazepines and identifying such people requires more than a little skill in psychiatric assessment. Secondly, there

before treatment is started. Unfortunately, several of the features associated with a greater risk of dependence may be recognised only after the drug has been prescribed. Higher doses and a prolonged duration of treatment are commonly reported in published studies of dependence on benzodiazepines, ${ }^{7}$ and at first sight these variables cannot be predicted in advance. When personality state is considered, however, the variables fall into place as secondary features and can be foreseen.

Premorbid personality is not easy to measure, although many doctors can detect an abnormality in personality without necessarily being able to describe it formally. Two types of personality disorder are associated with abuse of and dependence on benzodiazepines. The first is a group that was formerly included under the diagnostic label of "psychopath" but has more recently been better defined in the United States as borderline personality disorder. ${ }^{8}$ This type of personality is characterised by unstable mood and impulsive behaviour. Any form of mental distress leads to the demand for immediate gratification, and benzodiazepines, with their rapid onset of action, are often desired. This type of patient will often abuse benzodiazepines at high doses for short periods without becoming dependent, but if high consumption is prolonged dependence is likely.

The second type of abnormality of personality associated with dependence on benzodiazepines is the timid worrier, formerly described as the passivedependent ${ }^{9}$ or anxious ${ }^{10}$ personality disorder and now included under the diagnostic headings of dependent and avoidant personality disorders in the third revised edition of the Diagnostic and Statistical Manual of Mental Disorders." People with such personalities make up a large proportion of anxious patients in psychiatric practice ${ }^{12}$ and are often described as suffering from "chronic anxiety." Close examination shows, however, that these patients usually have a personality disturbance associated with their mood disorder and that benzodiazepines, although given for long periods in comparatively low doses have little or no effect on the underlying disease. Such patients have a higher incidence of withdrawal symptoms than others who have taken benzodiazepines long term. ${ }^{6}$

\section{Avoiding risk factors when prescribing benzodiazepines}

An important clinical skill is to recognise these personality characteristics before prescribing benzodiazepines. If they are recognised benzodiazepines will seldom if ever need to be prescribed. If this group

continued on page 104

St Charles's Hospital, London W10 6DZ

Peter Tyrer, FRCPSYCH, senior lecturer in psychiatry

BrMed f 1989;298:102-5 seems to be no dispute that long term use of benzodiazepines will commonly lead to withdrawal reactions, although the patient rather than the doctor may be the prime mover in ensuring that treatment is long term. Except in psychiatry, there seems to be little justification for prescribing benzodiazepines apart from for the short term alleviation of acute states of anxiety or insomnia.-PETER RUBIN, professor of therapeutics, University Hospital, Nottingham NG7 2UH 
Controversies in

\section{Therapeutics}

because benzodiazepines are medically prescribed to patients who are generally compliant. Nevertheless, $7 \cdot 5-10 \cdot 0 \mathrm{mg}$ lorazepam daily ${ }^{11}$ is not uncommon (equivalent to $75-100 \mathrm{mg}$ diazepam ${ }^{24}$ ).

Withdrawal symptoms occurring during long term use are more noticeable with potent benzodiazepines that are rapidly eliminated. Patients taking lorazepam ${ }^{5}$ or alprazolam ${ }^{25}$ commonly experience craving or dysphoria between doses, and daytime withdrawal effects from the use of triazolam as a hypnotic are well recognised." Thus the motivation to use benzodiazepines for anxiolysis or hypnosis gradually merges with the need to avoid withdrawal effects. For this reason it may be impossible to measure withdrawal effects precisely.

Recently Murphy et al broadened their withdrawal criteria to include a temporary increase in anxiety to less than initial values. ${ }^{26}$ In this study ratings before benzodiazepine were available and the incidence of withdrawal symptoms was again $30 \%$. Diazepam was, however, given for only six weeks and the results may not apply to those who use it for longer. Furthermore, many long term users (46 out of 86 in one study ${ }^{27}$ ) decline to undertake withdrawal and many drop out ( 18 of the remaining $40^{27}$ ) because of fear or experience of withdrawal. Taking account of these subjects would substantially raise the apparent incidence.

\section{Pharmacological mechanisms}

The pharmacodynamic mechanism of benzodiazepine tolerance and dependence is probably homoeostatic down regulation of $\gamma$-aminobutyric acid and benzodiazepine receptors in the limbic system. ${ }^{28}$ Once this has occurred, withdrawal of the drug results in a state of underactivity of pathways utilising $\gamma$-aminobutyric acid with a pattern of unapposed neuronal excitation characteristic of benzodiazepine withdrawal ${ }^{29}$ and anxiety states. $^{10}$ Similar brain mechanisms mediate the psychological and somatic symptoms of both conditions, which are in many respects inseparable.

Lader notes that even non-anxious people may develop benzodiazepine withdrawal symptoms, ${ }^{20}$ although they may be less prone to do so.? There may be a population of stable people who discard benzodiazepines without difficulty when a temporary stress has passed. I suggest, however, that most people who continue to use benzodiazepines are dependent on the drugs for enhancement of the effects of $\gamma$-aminobutyric acid. All will suffer withdrawal symptoms unless they withdraw slowly and simultaneously learn alternative strategies of coping. Long term control of anxiety probably requires learned changes in endogenous $\gamma$-aminobutyric acid transmission rather than the imposition of an exogenous cover up with benzodiazepines.

1 Parrott AC, Kentridge R. Personal constructs of anxiety under the 1,5 benzodiazepine clobazam related to trait-anxiety levels of the personality. Psychopharmacology 1982;75:353-7.

2 Parrott AC, Davies S. Effects of a 1,5 benzodiazepine upon performance in an experimental stress situation. Psychopharmacology 1983;79:367-9.

3.O'Boyle CA, Harris D, Barry H, Cullen JH. Differential effects of benzodiazepine sedation in high and low anxious patients in 'real life' stress setting. Psychopharmacology 1986;88:266-9.

4 Golding JF, Cornish AM. Personality and life-style in medical students: psychopharmacological aspects. Psychology and Health 1987;1:287-301.

5 Ashton H. Benzodiazepine withdrawal: an unfinished story. Br Med $\mathcal{f}$ 1984;288:1135-40.
Ashton H. Benzodian

6 Ashton H, Golding JF. Tranquillisers: prevalence and possible consequences: data from a large United Kingdom survey. Br $\mathcal{f}$ Addict (in press)

7 Murphy SB, Tyrer P. The essence of benzodiazepine dependence. In: Lader $\mathrm{M}$, ed. The psychopharmacology of addiction. Oxford: Oxford University Press, 1988:157-67.

8 Bond MR. Personality and pain. In: Lipton S, ed. Persistent pain: modern methods of treatment. Vol 2. London: Academic Press, 1980:1-26.

9 Leonard BE. New antidepressants and the biology of depression. Stress Medicine 1985;1:9-16.

10 Gray JA. The neuropsychology of anxiety. Oxford: Clarendon Press, 1982.

11 Ashton $\mathrm{H}$. Benzodiazepine withdrawal: outcome in 50 patients. $\mathrm{Br} \mathcal{F}$ Addict $1987 ; 82: 665-71$.

12 Gray JA. Interactions between drugs and behaviour therapy. In: Eysenk HJ, Martin I, eds. Theoretical foundations of behaviour therapy. New York: Plenum Press, 1987:433-47.

13 Tyrer $P$, Owen $R$, Dawling S. Gradual withdrawal of diazepam after long-term therapy. Lancet 1983;i:1402-6.

14 Gray JA. The neuropsychology of emotion and personality. In: Stahl SM Iverson SD, Goodman EC, eds. Cognitive neurochemistry. Oxford: Oxford University Press, 1987:171-90.

15 Iverson SD, Iverson LL. Behavioural pharmacology. New York: Oxford University Press, 1981.

16 Woods JH, Katz JL, Winger G. Abuse liability of benzodiazepines. Pharmacol Rev 1987;39:251-419.

17 Eysenck HJ, Eysenck SBG. Manual of the Eysenck personality questionnaire Essex: Hodder and Stoughton, 1975.

18 Petursson $\mathrm{H}$, Lader $\mathrm{MH}$. Withdrawal from long-term benzodiazepine treatment. Br Med f 1981;283:643-5.

19 Lader $\mathrm{MH}$, Olajide D. A comparison of buspirone and placebo in relieving benzodiazepine withdrawal symptoms. F Clin Psychopharmacol 1987;7: 11-5.

20 Lader M, ed. The psychopharmacology of addiction. Oxford: Oxford University Press, 1988:1-14.

21 Tyrer P, Rutherford D, Huggett T. Benzodiazepine withdrawal symptoms and propranolol. Lancet 1981;i:520-2.

22 Rickels K, Case WG, Downing RW, Winokur A. Long-term diazepam therapy and clinical outcome. $\mathscr{F} A M A$ 1983;250:767-71.

23 Busto U, Sellers EM, Naranjo CA, Cappell HP, Sanchez CM, Sykora K. Withdrawal reaction after long-term therapeutic use of benzodiazepines. N Engl F Med 1986;315:654-9.

4 Northern Regional Health Authority. Benzodiazepine dependence and withdrawal - an update. Drug Newsletter 1985;31:125-8.

25 Hermann JB, Brotman AW, Rosenbaum JF. Rebound anxiety in panic disorder patients treated with shorter-acting benzodiazepines. $\mathcal{f}$ Clin Psychiatry 1987;48(suppl 10):22-8.

26 Murphy SM, Owen R, Tyrer P. Comparative assessment of efficacy and withdrawal symptoms after six and twelve weeks treatment with diazepam or buspirone Brf Psychiorn (in press).

27 Tyrer P. Round table discussion. In: Costa E, ed. The benzodiazepines: from molecular biology to clinical practice. New York: Raven Press, 1983:400-6.

28 Nutt D. Benzodiazepine dependence in the clinic: reason for anxiety? Trends in Neurosciences 1986;9:547-60.

29 Cowen PJ. Psychotropic drugs and human 5-HT neuroendocrinology. Trends in Pharmacological Sciences 1987;8:105-8.

30 Ashton H. Brain systems, disorders, and psychotropic drugs. Oxford: Oxford University Press, 1987.
Peter Tyrer

continued from page 102 is excluded the features associated with dependencehigh dosage, long duration of treatment, and previous dependence on psychotropic drugs - are avoided and the prescription becomes short term, low dosage, and comparatively free of risk (table). Doctors need to realise that benzodiazepines now have no value in long

Influence of premorbid personality on factors predisposing to dependence on benzodiazepines

\begin{tabular}{|c|c|c|}
\hline \multirow[b]{2}{*}{ Risk factor } & \multicolumn{2}{|c|}{ Type of premorbid personality } \\
\hline & Normal & Dependent \\
\hline Dose & Low & Variable \\
\hline Frequency & Intermittent & Regular \\
\hline Duration of treatment & Short & Long \\
\hline $\begin{array}{l}\text { Previous dependence on prescribed } \\
\text { psvchotropic drugs }\end{array}$ & Rare & Common \\
\hline Nature of benzodiazepine & $\begin{array}{l}\text { Determined by } \\
\text { prescriber }\end{array}$ & $\begin{array}{l}\text { Determined } \\
\text { by prescriber }\end{array}$ \\
\hline
\end{tabular}

term prescribing. These drugs should not be given for longer than four weeks; if given for longer they are less effective than antidepressants and psychological procedures such as cognitive therapy and self help packages. ${ }^{13}$ They should be confined to short term intervention when rapid relief of anxiety and insomnia is considered to be essential. In making the decision to prescribe benzodiazepines doctors need to diagnose symptoms, circumstances, and person. If they do this successfully they have no reason to fear dependence.

1 Murphy SM, Tyrer P. The essence of benzodiazepine dependence. In: Lader $\mathrm{M}$, ed. The psychopharmacology of addiction. Oxford: Oxford University Press, 1988;157-67.

2 Petursson $\mathrm{H}$, Lader $\mathrm{MH}$. Withdrawal from long-term benzodiazepine treatment. Br Med F 1981;283:643-5.

3 Ashton $\mathrm{H}$. Benzodiazepine withdrawal: an unfinished story. $\mathrm{Br}$ Med $\mathrm{f}$ 1984;288:1135-40.

4 Busto U, Sellers EM, Naranjo CA, Cappell H, Sanchez-Craig M, Sykora K. Withdrawal reaction after long-term therapeutic use of benzodiazepines. $N$ Engl f Med 1986;315:854-9. 
5 Tyrer $\mathrm{P}$, Rutherford D, Huggett T. Benzodiazepine withdrawal symptom and propranolol. Lancet $1981 ; \mathrm{i}: 520-2$.

6 Tyrer $\mathrm{P}$, Owen R, Dawling S. Gradual withdrawal of diazepam after long-term therapy. Lancet 1983;i:1402-6.

7 Owen RT, Tyrer P. Benzodiazepine dependence: a review of the evidence. Drugs 1983;25:385-98.

8 Gunderson JG, Singer MT. Defining borderline patients: an overview. $A m \mathcal{f}$ Psychiatry 1975;132:1-10.

9 Tyrer P, Alexander J. Classification of personality disorder. Br $\mathcal{F}$ Psychiatry 1979;135:163-7.
10 Mann AH, Jenkins R, Cutting JC, Cowen PJ. The development and use of a standardised assessment of abnormal personality. Psychol Med 1981;11:839-

11 American Psychiatric Association. Diagnostic and statistical manual of mental disorders. 3rd ed, revised. Washington, DC: APA, 1987.

12 Tyrer $\mathrm{P}$, Casey $\mathrm{P}$, Gall $\mathrm{J}$. The relationship between neurosis and personality disorder. Brf Psychiatry 1983;142:404-8.

13 Tyrer P, Seivewright N, Murphy S, et al. The Nottingham study of neurotic disorder: comparison of drug and psychological treatments. Lancet 1988;ii: $235-40$

\section{Boxing and the brain}

\section{J A N Corsellis}

The American pathologist Martland wrote a paper entitled "Punch drunk" in 1928, in which he drew attention for the first time to a "peculiar condition among prize fighters." "Many cases remain mild, but in severe cases," he wrote, "there may develop a peculiar tilting of the head, a marked dragging of one or both legs, a staggering, propulsive gait with the facial characteristics of the parkinsonian syndrome, or a backward swaying of the body, tremors, vertigo, or deafness. Finally, marked mental deterioration may set in necessitating commitment to an asylum."

Such changes, even when mild, are now rarer. Control of the sport, while varying greatly from country to country, has been considerably tightened up, and the authorities in the United Kingdom have worked hard to minimise the dangers. Nevertheless, hitting people on the head must always carry some risk to the brain, and as long as the sport is encouraged as a noble activity by some its existence is bound to be questioned by others.

Two forms of damage may occur. Firstly, there is the remote risk of death in the ring or within a few days after the fight - a catastrophe usually caused by bleeding inside the head. ${ }^{2}$ This risk in boxing seems to be no greater than that in other sports, although accurate mortality figures do not exist. ${ }^{3}$ Indeed, McCunney and Russo found that the threat to life was less than that in sports ranging from college football and horse racing to hang gliding and scuba diving. ${ }^{4}$ Sammons, however, uncovered a greater risk to American boxers during the 1970s. ${ }^{5}$ Secondly, and perhaps more importantly, there is the risk of unremitting disease in those who survive a career in boxing, and it is this kind of damage that is least discussed. Repeated sublethal blows to the head, whether or not they cause a knockout, may lead to insidious changes that may underlie the punch drunk state $^{1}$ or Millspaugh's dementia pugilistica. ${ }^{\circ}$ The many neurological facets of the punch drunk state have been reported by neurologists in the United Kingdom $^{7-11}$ and, more recently, the United States. ${ }^{312}$ The pathological aspects, however, have been less often studied. Perhaps an element of serendipity enters into the supply of brains of former boxers, for most studies have been based on the microscopical examination of a single or a few brains. The pathological focus has consequently tended to fall on one or other kind of change to the detriment of any more comprehensive pattern that might underlie the features of "punch drunkenness."

The ethical criticisms of boxing have been smouldering in Britain for some years. In 1956 Edith Summerskill published a polemic entitled The Ignoble Art, in which she warned of the dangers to the brain and eye. ${ }^{13}$ In 1964 a symposium on the medical aspects of boxing was held in London, when the arguments were outspoken but inconclusive. ${ }^{14}$ Neuropathology was scarcely touched on, and by the end most lay experts and some doctors cast doubt, and even scorn, on the idea that the brain could be at risk in such a worthy and enjoyable sport. Four years later, before his clinical assessment of over 200 former boxers, Roberts wrote that "there has been no specific pathological evidence to confirm the assumption that boxing is causally related to the clinical syndrome described." 10

\section{Neuropathological observations}

In his prescient way Martland noted that "the late manifestations of punch drunk will be seen chiefly in the neurologic clinics and asylums and such material will practically fall to the neuropathologist connected with such institutions." Cases did begin to become available - in 1957 - to the neuropathological departments of Runwell Psychiatric Hospital, Essex, and the Institute of Psychiatry in London. The findings added weight to the critical view of Summerskill, ${ }^{13}$ although the original project had begun merely as a clinical and pathological inquiry into the late effects on movement, memory, and mental state of repeated blows to the heads of 15 men, all of whom had boxed in their youth. ${ }^{15}$ The pros and cons of the sport became of interest only after the findings had been analysed. These findings were often complex, and they varied in severity; in one case no neurological damage was found. Four main sites of change were described.

Septal regions-The most obvious abnormality, seen in 11 of 13 cases, was centred on the deep midline structures. The septa were wide apart, torn, and fenestrated, and often only tags survived. The ventricles were enlarged and the fornices atrophied. Spillane had first illustrated these anomalies by air encephalography. ${ }^{8}$ On microscopy the tissue in this area, including the thalamus and hypothalamus, ${ }^{16}$ showed severe gliosis partially reminiscent of the Wernicke-Korsakoff syndrome.

Cerebellum and substantia nigra-Perhaps the most striking clinical features of punch drunkenness lie in the disordered movement, summarised by Roberts as forming "a relatively stereotyped pattern. At its mildest, this consisted of dysarthria with or without disequilibrium and spasticity, or rigidity and striatal tremor associated with varying degrees of dementia. All grades of disturbed neurological function in cerebellar, pyramidal and extra-pyramidal systems were apparent between these extremes."10 The motor pathways in the cerebellum and the substantia nigra were affected

In the cerebellum atrophy and glial fibrosis affected those folia that were encircled by the foramen magnum. In addition there was a pronounced loss of Purkinje cells (confirmed by cell counts) in the undersurface of the cerebellum. In the substantia nigra the most obvious lesion, often apparent to the naked eye, was the lack of the large pigmented neurones, which is the classical neuropathological feature of a parkinsonian state.

Neurones - The most inexplicable alteration in the
J A N Corsellis, FRCPSYCH, neuropathology

BrMed f 1989;298: 105-9 